\title{
The aetiology of mesothelioma: are risk factors other than asbestos exposure important?
}

\author{
Richard Hubbard
}

Mesothelioma is an important cause of mortality in England and Wales, accounting for over 1000 deaths each year. ${ }^{1}$ The incidence of mesothelioma is rising and, if the predictions of Peto et al are correct, then by the year 2020 there will be approximately 3000 deaths a year from mesothelioma, with $1 \%$ of men currently aged $49-54$ years dying from this disease. ${ }^{1}$ There is a wealth of epidemiological and experimental evidence supporting a strong association between asbestos exposure and mesothelioma. ${ }^{2}$ Do we need to look any further for other causes of this disease?

In this issue of Thorax Yates et al report the clinical and pathological characteristics of all patients with mesothelioma diagnosed within the south east of England in $1987^{3}$ and, of the 272 cases reviewed, 30 (11\%) had no evidence of exposure to asbestos. Others have reported similar rates of asbestos exposure amongst patients with mesothelioma. ${ }^{4-6}$ It seems likely, therefore, that a few patients develop disease without exposure to asbestos, although under-reporting of exposure and over-diagnosis may explain some of these cases. The problem of unrecognised asbestos exposure is a particularly important public health issue for, in spite of the fact that the risk of asbestos exposure was first noted in workers within the asbestos industry, a large proportion of cases now occur in workers in other occupations where exposure may not be well controlled and not appreciated by the worker. The high proportion of carpenters, electricians, and construction workers in the series reported by Yates et $a l^{3}-$ occupations which have been noted before to be high risk ${ }^{1}$ - is probably a reflection of this.

Cases of mesothelioma unrelated to asbestos exposure may occur either spontaneously or in response to environmental insults. Evidence for the existence of spontaneous disease is provided mainly by studies in children. ${ }^{78}$ Mesothelioma is a rare tumour in this age group, but one survey of 80 cases in children of mean age 9.7 years has been conducted and a history of asbestos exposure was present in only two children. ${ }^{7}$ In adults there is little increased risk of mesothelioma for the first 20 years following exposure to asbestos ${ }^{9}$ and, therefore, unless the natural history of asbestos related disease is different in children, cases of mesothelioma in this age group are not due to unrecognised exposure. Further evidence to support spontaneous disease comes from reports of malignant pleural tumours diagnosed at the end of the last century before the introduction of the industrial use of asbestos. ${ }^{2}$ A local epidemic of mesothelioma in central Cappadocia, Turkey ${ }^{10}$ where, in one village, nearly a quarter of all deaths were due to mesothelioma has highlighted exposure to other environmental mineral fibres as a potential aetiological risk factor. The rocks in this region were found to contain zeolite minerals such as erionite, traces of which were present in the air of the villages. Erionite has been shown to cause mesothelial tumours in experimental animals. ${ }^{11}$ Other possible aetiological agents, identified on the basis of anecdotal reports, include exposure to sugar cane, ${ }^{12}$ ionising radiation, ${ }^{13}$ and the presence of pleural scars following empyema or therapeutic pneumothorax. ${ }^{14}$

For mesothelioma associated with asbestos exposure it is possible that other factors may act synergistically with asbestos in causing disease. A familial cluster of five cases of mesothelioma has been reported which suggests a role for genetic susceptibility. ${ }^{15}$ However, in this family four of the cases worked in the building trade and therefore unrecognised asbestos exposure cannot be excluded. A high prevalence of smoking amongst patients with mesothelioma has been noted before ${ }^{16}$ but, in a controlled study, no significant association was found. ${ }^{17}$ An interesting new development is the possible role of Simian virus 40 (SV40) as a risk factor for mesothelioma. This virus contaminated the polio vaccine in the late 1950 s and early 1960s and was accidentally inoculated into millions of people in Europe and the USA. ${ }^{18}$ Experimentally, SV40 has been shown to induce pericardial and pleural mesothelioma in hamsters $^{19}$ and the presence of SV40 DNA has recently been identified in a number of pathological specimens of mesothelioma. ${ }^{2021}$

In summary, most cases of mesothelioma may be explained by exposure to asbestos but spontaneous disease does occur and other mineral and organic fibres may be important in the aetiology of some cases. The role of SV40 as a possible co-carcinogen with asbestos in the aetiology of mesothelioma requires further investigation, particularly in view of the continuing rise in mortality in the UK from this disease.

Division of Respiratory Medicine,

Nottingham City Hospital,

Hucknall Road,

Nottingham NG5 4LQ, UK

1 Peto J, Hodgson JT, Matthews FE, Jones JR. Continuing increase in mesothelioma mortality in Britain. Lancet 1995;345:535-9.

2 McDonald JC, McDonald AD. The epidemiology of mesothelioma in historical context. Eur Respir f 1996;9:1932-42.

3 Yates DH, Corrin B, Stidolph PN, Browne K. Malignant mesothelioma in south east England: clinicopathological experience of 272 cases. Thorax south east Englan

4 Greenberg M, Lloyd Davies TA. Mesothelioma register 1967-68. Br f Ind Med 1974;31:91-104.

5 Milne JEH. Thirty-two cases of mesothelioma in Victoria, Australia: a rectrospective survey related to occupational asbestos expsoure. $\mathrm{Br} F$ Ind Med 1976;33:115-22.

6 Spirtas R, Heineman EF, Bernstein L, Beebe GW, Keehn R, Stark A, et al. Malignant mesothelioma: attributable risk of asbestos exposure. Occup Environ Med 1994;51:804-11.

7 Fraire AE, Cooper S, Greenberg SD, Buffler P, Langston C. Mesothelioma of childhood. Cancer 1988;62:838-47.

8 Lin-Chu M, Lee Y, Ho MY. Malignant mesothelioma in infancy. Arch Pathol Lab Med 1989;113:409-11.

9 Peto J, Seidman H, Selikoff IJ. Mesothelioma mortality in asbestos workers: implications for models of carcinogenesis and risk assessment. $\mathrm{Br} f$ Cancer 1982;45:124-35.

10 Baris I, Simonato L, Artvinli M, Pooley F, Saracci R, Skidmore J, et al. Epidemiological and environmental evidence of the health effects of Exposure to erionite fibres: a four year study in the Cappadocian region exposure to erionite fibres: a four year

11 Wagner JC, Skidmore JW, Hill RJ, Griffiths DM. Erionite exposure and Wagner JC, Skidmore JW, Hill RJ, Griffiths DM. E
mesothelioma in rats. Br f Cancer 1985;51:727-30.

12 Das PB, Fletcher AG, Deodhare SG. Mesothelioma in an agriculatural community of India: a clinicopathological study. Aust NZ f Surg 1976; 46:218-26.

13 Lerman Y, Learman Y, Schachter P, Herceg E, Lieberman Y, Yellin A Radiation associated malignant pleural mesothelioma. Thorax 1991;46 463-4.

14 Hillerdal G, Berg J. Malignant mesothelioma secondary to chronic inflammation and old scars. Cancer 1985;55:1968-72. 
15 Risberg B, Nickels J, Wagermark J. Familial clustering of malignant mesothelioma. Cancer 1980;45:2422-7.

16 Peterson JT, Greenberg D, Buffler PA. Non-asbestos-related mesothelioma. Cancer 1984;54:951-60.

17 McDonald AD, McDonald JC. Malignant mesothelioma in North America. Cancer 1980;46:1650-6.

18 Shah K, Nathanson N. Human expsoure to SV40: review and comment. Am f Epidemiol 1976;103:1-12.
19 Cicala C, Pompetti F, Carbone M. SV40 induces mesotheliomas in hamsters. Am $\mathcal{F}$ Pathol 1993;142:1524-33.

20 Pepper C, Jasani B, Navabi H, Wynford-Thomas D, Gibbs AR. Simian irus 40 large $T$ antigen (SV40LTAg) primer specific DNA amplification in human pleural mesothelioma tissue. Thorax 1996;51:1074-6.

21 Carbone M, Pass H, Rizzo P, Marinette MR, Di Muzio M, Mew DJY, et al. Simian virus-like DNA sequences in human pleural mesothelioma. Oncogene 1994;9:1781-90. 